\title{
Comparison between operative and non operative treatment of fracture shaft of humerus: an outcome analysis
}

\author{
Sanjeev Kumar ${ }^{1}$, Natarajan Shanmugam ${ }^{2} *$, Sandeep Kumar ${ }^{3}$, Kalanithi Ramanusan ${ }^{2}$
}

Department of Orthopedics, ${ }^{1}$ Hindu Rao Hospital, Delhi, ${ }^{2}$ Saveetha Medical College, Thandalam, Chennai, Tamil Nadu, ${ }^{3}$ Government Hospital, Sri Ganga Nagar, Rajasthan, India

Received: 18 March 2017

Revised: 01 April 2017

Accepted: 06 April 2017

\section{*Correspondence: \\ Dr. Natarajan Shanmugam, \\ E-mail: drsnats@gmail.com}

Copyright: () the author(s), publisher and licensee Medip Academy. This is an open-access article distributed under the terms of the Creative Commons Attribution Non-Commercial License, which permits unrestricted non-commercial use, distribution, and reproduction in any medium, provided the original work is properly cited.

\begin{abstract}
Background: Humerus shaft fractures account for $3 \%$ of all orthopaedic injuries. Many modalities of treatment are available. Conservative treatment has been the mainstay of treatment. But now due to improvements in anaesthesia, implant design many patients having fracture shaft of humerus are operated.

Methods: We compared the operative and non operative modalities of treatment in this prospective randomised controlled trial. In 40 patients, twenty patients were treated surgically and twenty were treated non surgically between May 2012 to June 2014 in Hindu Rao Hospital, New Delhi.

Results: Our results show faster union in non-operative patients but functional DASH scores are significantly better in operated patients. Complications are comparable in both groups.

Conclusions: Operative treatment for fracture shaft humerus gives better functional results in this study. Dynamic compression plating of humerus is better method than conservative method and avoids prolonged immobilization. Larger multicentric trials comparing functional cast bracing and plating are needed.
\end{abstract}

Keywords: Fracture shaft of humerus, Comparative study, Plate vs. functional cast bracing

\section{INTRODUCTION}

New faster modes of transport and industrialisation led to an increase in trauma cases throughout the world. Humerus shaft fractures account for $3 \%$ of all orthopaedic injuries. ${ }^{1}$ Characterized by a bimodal age distribution, they peak in 21 to 30 age bracket primarily in male patients, and the second peak being between 60 to $80 \mathrm{yrs}$ in older female patients. This leads to decreased productivity and thus are a burden for the society. ${ }^{2-4}$

Non operative management had been the mainstay of treatment for fracture shaft of humerus. ${ }^{5}$ Non-operative treatment involves the use of casts, functional braces or supervised neglect. However focus is now shifting from achieving merely the union of bone to achieve perfect axial alignment, length and rotational stability. For the same reasons and also because of the prolonged period of immobilisation associated with conservative management, operative modalities of treatment are increasingly being performed.

One of the commonly used operative modality is dynamic compression plating. Plate fixation when combined with open reduction provides direct fracture visualisation, allows anatomical reduction and rigid fracture fixation. A stable fixation allows early mobilization of the affected extremity and thus prevents muscle atrophy, joint stiffness and osteoporosis and an early return to normal activity. 
In view of above considerations, a study was undertaken which aimed to compare non-operative treatment with dynamic compression plating (DCP) for the management of fracture shaft of humerus. The goal of our study was to determine whether dynamic compression plating of humerus shaft fractures would result in decreased time for union, better functional outcome and fewer complications in operative group.

\section{METHODS}

Our study was a prospective randomised control trial. After obtaining institutional review board approval, patients with fracture shaft of humerus were recruited in the study. It was carried out from May 2012 to June 2014 in Hindu Rao Hospital, New Delhi. Patients with age less than 16 years of age, Pathological fracture, segmental fractures and open fractures were excluded. A total of 40 patients were included and were randomised in to one of the two groups, Conservative and operative using a random number table after obtaining their consent are included in the study.

\section{Conservative group}

The patients in this group were managed either with $U$ slab or hanging cast application. This was exchanged with a functional cast 3-4 weeks after injury. These patients were managed on an outpatient basis and were admitted only when they had other serious injuries or associated fracture. The Functional cast was retained for 8 weeks or until radiographic union of fracture was evident.

\section{Operative group}

The patients in the operative group were immobilised using a $U$ slab on presentation to the emergency and underwent the surgical procedure once deemed fit for anaesthesia. Maximum number of patients $10(50 \%)$ were operated within 2 to 6 days of injury. $8(40 \%)$ patients were operated within 7 to 11 days of injury. The surgery was done using anterolateral or posterior approach with minimal periosteal stripping. Reduction of fragments were done anatomically and fixed with Dynamic Compression Plate using at least 6 cortical purchases on either side of fracture site (Figure 5). Thorough wash given, heamostasis was achieved and wound closed in layers. The operated upper limb was immobilized in an arm pouch. Suture removal was done on 12th postoperative day. Patients were discharged with the arm pouch.

\section{Follow up}

Patients were followed up for a period of 6 months at regular intervals. Local examination of the affected arm was done for tenderness, instability, deformity and shoulder and elbow movements. X-rays were taken at follow up visits to know about progression in fracture union. Rehabilitation protocol of the patient consisted of shoulder, elbow, forearm \& wrist exercises and was done according to the stage of fracture union and time duration from day of surgery. Patients were advised to avoid lifting weight or putting additional stresses on the affected limb. Patients were followed up till radiological union was seen.

\section{Outcome measures}

The primary outcome measures were time for union, presence of complications and DASH scores at end of follow up period. The patients in both the groups were followed until radiological union. Union was defined by the absence of functional pain and local tenderness at the previous fracture site and the presence of bridging callus in 3 of the 4 cortices seen on AP and Lateral views. The time taken for union in both these groups was recorded. Complications in these groups including malunion, nonunion, residual deformity, nerve injury and infections were recorded throughout the follow up period.

The functional outcome was measured by the "Disabilities of arm, shoulder and hand (DASH)", Questionnaire at time of 6 months or at full recovery which ever was earlier in both these groups. ${ }^{6}$

\section{Statistical analysis}

Continuous variables are presented as mean \pm SD, and categorical variables are presented as absolute numbers and percentage. The comparison of normally distributed continuous variables between the groups was performed using Student's t test. Nominal categorical data between the groups were compared using Chi-squared test or Fisher's exact test as appropriate. $\mathrm{P}<0.05$ was considered statistically significant. Statistical testing was conducted with the statistical package for the social science system version SPSS 17.0 Microsoft excel was used to draw tables, bar diagram and for the statistical analysis.

\section{RESULTS}

There were total 29 male patients out of 40 and 11 were females. In operative group there were 15 males and 5 females, the ratio being $3: 1$. In non-operative group male patients were 14 and female patients were 6 , the ratio being 7:3.9 (Table 1). Age varied between 18-83 years with maximum patients in 18-28 year age group both in operative and non-operative group. The mean age of the patients was 37.65 years in operative group and 32.7 years in non-operative group (Table 2). Left was the most commonly involved side in both the groups (12 patients on either group). In both group Road Traffic Accident was the common mode of injury (55\% and 60\%). In nonoperative group $4(20 \%)$ had fall and in operative group 5 patients had direct trauma. In either group $10 \%$ had twisting injury. 
Table 1: Sex distribution.

\begin{tabular}{|lll|}
\hline Sex & $\begin{array}{l}\text { No. of patients } \\
\text { Operative group }\end{array}$ & Non-operative group \\
\hline Male & $15(75 \%)$ & $14(70 \%)$ \\
\hline Female & $5(25 \%)$ & $6(30 \%)$ \\
\hline Total & $20(100 \%)$ & $20(100 \%)$ \\
\hline
\end{tabular}

Table 2: Age distribution.

\begin{tabular}{|lll|}
\hline $\begin{array}{l}\text { Age group } \\
\text { in years }\end{array}$ & $\begin{array}{l}\text { No. of patients } \\
\text { Operative } \\
\text { group }\end{array}$ & Non-operative group \\
\hline $\mathbf{1 8 - 2 8}$ & $7(35 \%)$ & $8(40 \%)$ \\
\hline $\mathbf{2 9 - 3 9}$ & $6(30 \%)$ & $5(25 \%)$ \\
\hline $\mathbf{4 0 - 5 0}$ & $4(20 \%)$ & $2(10 \%)$ \\
\hline $\mathbf{5 1 - 6 1}$ & $1(5 \%)$ & $2(10 \%)$ \\
\hline $\mathbf{6 2 - 7 2}$ & $1(5 \%)$ & $0(0 \%)$ \\
\hline $\mathbf{7 3 - 8 3}$ & $1(5 \%)$ & $0(0 \%)$ \\
\hline Total & $20(100 \%)$ & $20(100 \%)$ \\
\hline
\end{tabular}

Table 3: No. of unions.

\begin{tabular}{|c|c|c|c|}
\hline \multirow[b]{2}{*}{ Group } & \multicolumn{2}{|c|}{ No. of patients } & \multirow[b]{2}{*}{ P value } \\
\hline & $\begin{array}{l}\text { No. of } \\
\text { union }\end{array}$ & $\begin{array}{l}\text { No of non } \\
\text { union }\end{array}$ & \\
\hline Operative group & $19(95 \%)$ & $1(5 \%)$ & \multirow{3}{*}{1.000} \\
\hline $\begin{array}{l}\text { Non-operative } \\
\text { group }\end{array}$ & $18(90 \%)$ & $2(10 \%)$ & \\
\hline Total & $20(100 \%)$ & $20(100 \%)$ & \\
\hline
\end{tabular}

Table 4: Functional outcome.

\begin{tabular}{|c|c|c|c|}
\hline \multirow[b]{2}{*}{ No. of weeks } & \multicolumn{2}{|c|}{ No. of patients } & \multirow[b]{2}{*}{ P value } \\
\hline & $\begin{array}{l}\text { Operative } \\
\text { group }\end{array}$ & $\begin{array}{l}\text { Non- } \\
\text { operative } \\
\text { group }\end{array}$ & \\
\hline Excellent & $10(50 \%)$ & $2(10 \%)$ & \multirow{4}{*}{$<0.0001$} \\
\hline Good & $6(30 \%)$ & $6(30 \%)$ & \\
\hline Fair & $2(10 \%)$ & $8(40 \%)$ & \\
\hline Poor & $2(10 \%)$ & $4(20 \%)$ & \\
\hline
\end{tabular}

The most common site of fracture in both group was middle $1 / 3(65 \%$ and $60 \%)$ with lower $1 / 3$ being second most common. According to OTA classification $80 \%$ of operated patients had A3, 15\% had A2, 5\% had
A1fractures. In non-operative group 55\% had A2, 20\% had A2, 20\% had A3 and 5\% had B2 fractures.

In operative and non operative group number of fracture union were comparable. $1(5 \%)$ non-union in operative group and $2(10 \%)$ non-union in non-operative group (Table 3). The standard deviation for operative and non operative group was 5.21 and 6.206957 respectively. Statistically there was significant difference among two groups ( $\mathrm{p}$ value $<0.01$ ).

Fractures in operative group united at an average of 15.37 weeks and in non- operative group united at an average of 11 weeks. In non-operated patients fracture union is seen in $85 \%$ of the patients (17) in less than 12 weeks while in operated patients only $47.4 \%$ united in less than 12 weeks. The $\mathrm{P}$ value is $0.014 \%$ which is statistically significant (Figure 1).

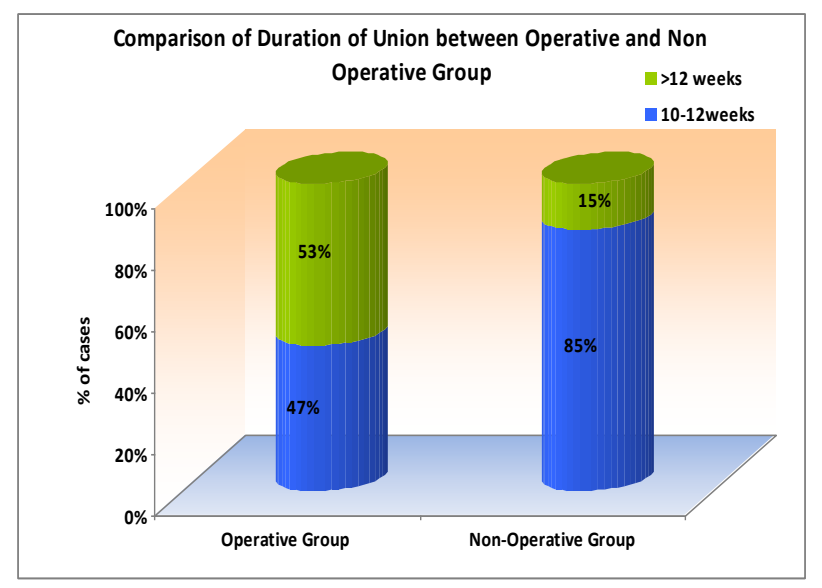

Figure 1: Comparison of duration of union between operative and non-operative group.

There were 2 non-unions in non- operative group and 1 non-union in operative group. Among the 40 patients 12 had excellent results, 12 had good, 10 had fair and 6 had poor results. Functional outcome scores were better for operative group as compared to non- operative group with $\mathrm{P}$ value $<0.0001$ (Table 4). DASH score of 0 to 20 was taken as excellent, 21 to 40 as good, 41 to 60 was taken as fair and above 61 was taken as poor. The average DASH score of the operative group was 23.4 and in the non operative it was 41.35. The results were statistically significant with $\mathrm{p}$ value of 0.007 (Table 5).

Table 5: DASH score.

\begin{tabular}{|c|c|c|c|c|c|}
\hline & \multicolumn{2}{|c|}{ Operative group $(n=20)$} & \multicolumn{2}{|c|}{ Non-operative group $(\mathrm{n}=20)$} & P Value \\
\hline \multirow{4}{*}{ DASH Score } & Mean \pm SD & Min - Max & Mean \pm SD & Min - Max & \\
\hline & $23.40 \pm 22.87$ & $0-85$ & $41.35 \pm 16.32$ & $16-65$ & 0.007 \\
\hline & Median & IQR & Median & IQR & \\
\hline & 20 & $2.5-29.75$ & 42.5 & $30-59$ & 0.002 \\
\hline
\end{tabular}




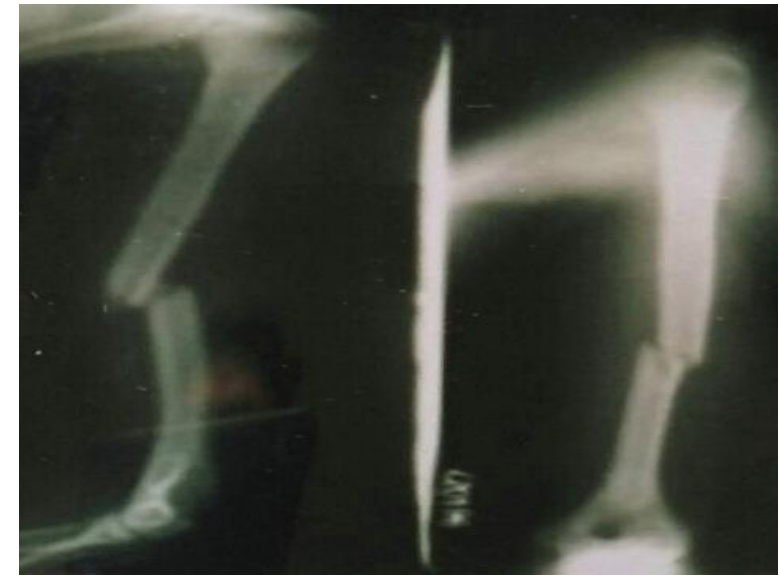

Figure 2: Immediately after trauma.

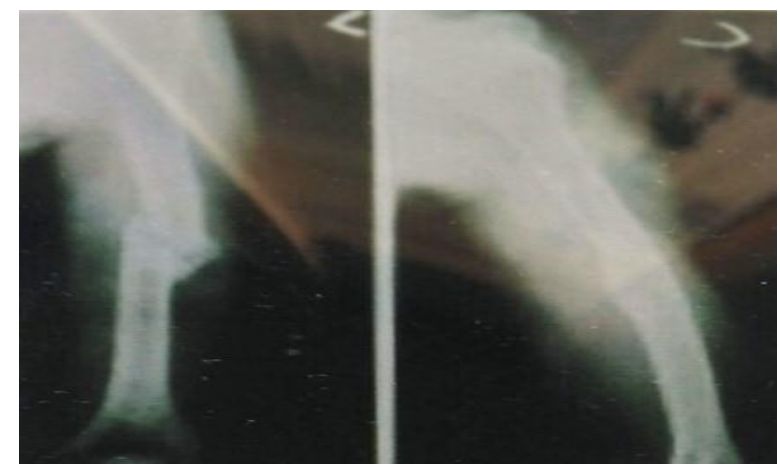

Figure 3: After 12 weeks in cast brace.

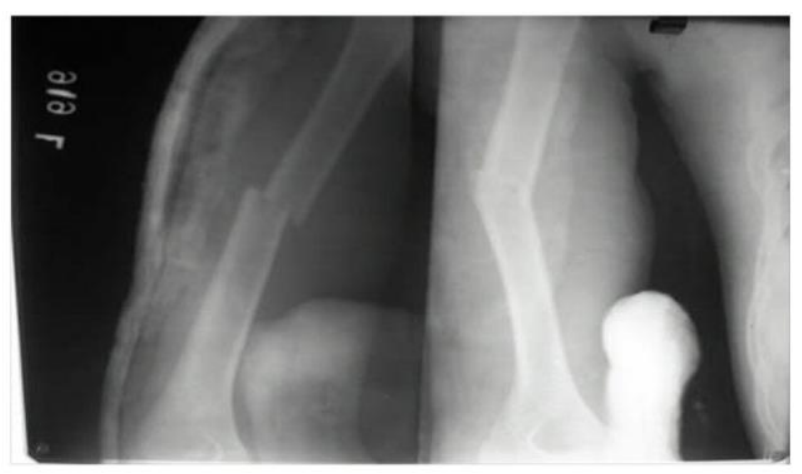

Figure 4: Preoperatively.

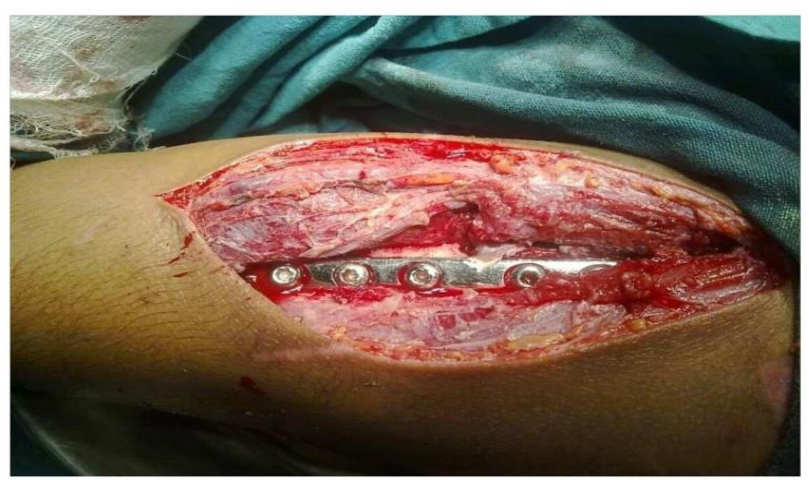

Figure 5: Intra operative photo showing DCP.

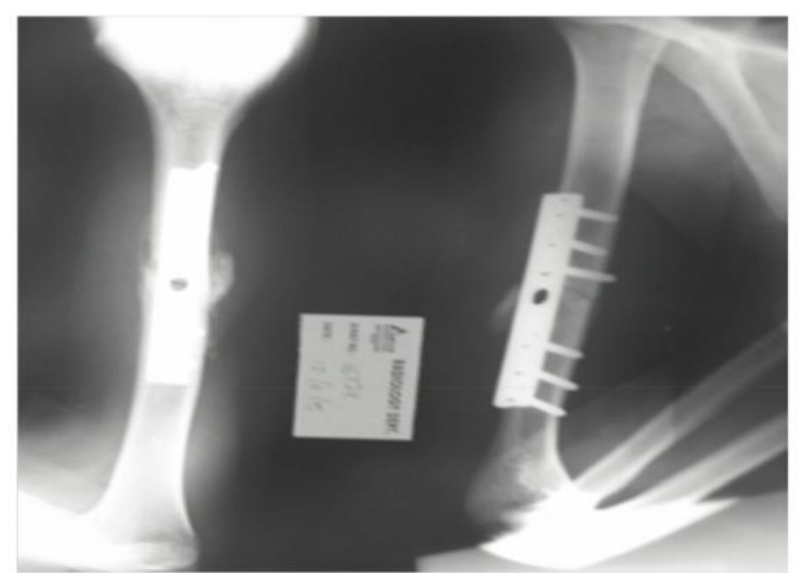

Figure 6: 6 weeks postoperatively.

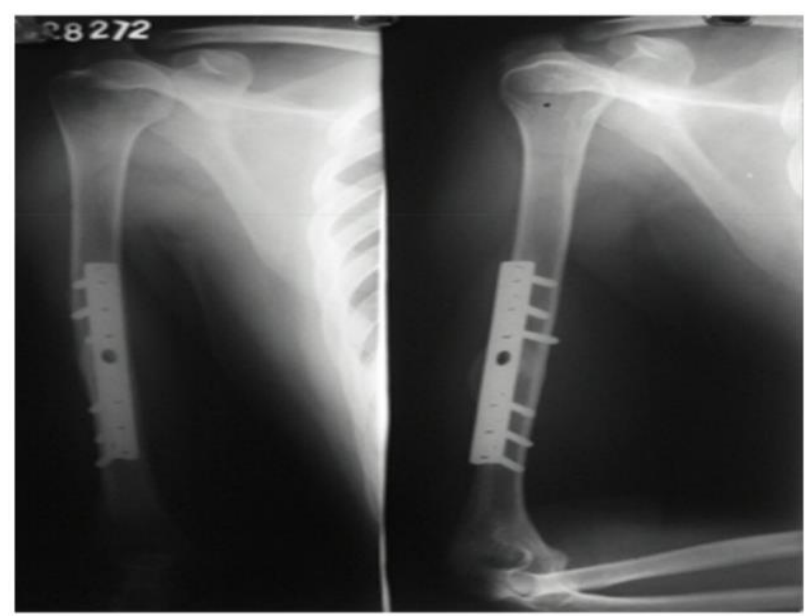

Figure 7: 12 weeks postoperatively.

\section{DISCUSSION}

In the Cochrane review done by Gosler et al there is no evidence from randomised controlled trials to inform the choice between surgical and non-surgical interventions for treating humeral shaft fractures in adults. ${ }^{7}$ Foster et al conducted a multicenter study in Seattle and found that plate osteosynthesis achieves best results in fresh fractures. $^{8}$

In our study average time for union in patients treated non-operatively was 11 weeks. In patients treated operatively average time for union was 15.37 weeks similar to the study done by Bell et al who in his study treated 38 patients by DCP fixation. ${ }^{9}$

Functionally patients in the operative group performed significantly better than non-operative group. DASH scores were significantly better for patients treated operatively.

In our study complications seen include 3 operated patients $(15 \%)$ had superficial infections which were managed with antibiotics and dressings. Within 3 weeks 
wound healed well. $2(10 \%)$ patients complained of hardware irritation and shoulder pain. 1 of them underwent plate removal while 1 refused for resurgery. 1 (5\%) patient had implant failure with screw back out from the plate, he was managed with arm pouch immobilisation as he refused for resurgery. 1 patient had post-operative radial nerve palsy. The patient had complete recovery by 16 weeks. None of the patient in the non-operative group had radial nerve palsy after immobilization. Delayed union was seen in $2(10 \%)$ patients in whom fracture united at 20 and 24 weeks. 1 patient had non-union. The cause of non-union in him was screw projecting into the fracture site. Among nonoperative group non-union was seen in 2 patients but they were satisfied with their appearance and function so they refused for surgery. 3 of the patients had malunion, no treatment was given to them. Delayed union was seen in 4 patients in whom fracture united at $18-20$ weeks. The rate of non-union in study done by Healy was $13 \%$ and $8 \%$ in non-operative and operative groups respectively while in our study it was $5 \%$ and $10 \%$ respectively. ${ }^{10}$ There was a significant reduction in the risk of non-union in the operative group compared with the non operative group. The incidence of non-union has been reported to be as high as $39 \%$ with conservative management (functional bracing) in a study done by Rutgers and Ring. ${ }^{11}$

In the study by Mahabier et al the data indicated that consolidation time and complication rates were similar after operative and non-operative treatment while in our study rapid functional restoration and patient satisfaction was better in the operative group. ${ }^{12}$ The improvement in scores was clinically relevant as well as significant statistically. This is similar to study by Denard et al who in their retrospective study of 213 patients found a statistically significant difference in the occurrence of nonunion $(20.6 \%$ versus $8.7 \%$ ) and malunion $(12.7 \%$ versus $1.3 \%$ ), more common in the nonoperative group. ${ }^{13}$ We agree with Nicholas that larger multicentre trials comparing functional cast bracing and plating are needed as the incidence of fracture shaft humerus is less. ${ }^{14}$

\section{CONCLUSION}

Our study suggested that rigid internal fixation and early mobilisation of fresh fracture shaft of humerus gives immediate pain relief and prevents development of shoulder and elbow stiffness and is associated with lower incidence of nonunion. Our results show faster union in conservatively treated patients but functional DASH scores are better in operated patients. Dynamic compression plating of humerus is better method than conservative method and avoids prolonged immobilization. It also gives early active and pain free mobilization. With correct anatomical knowledge, good preoperative planning, minimal soft tissue dissection, adherence to AO principles, asepsis precautions, postoperative physiotherapy, patient education and early mobilization, the dynamic compression plating of fracture shaft of humerus gives good results as compared to non operative management. Larger multicentric trials comparing functional cast bracing and plating are needed.

\section{Funding: No funding sources \\ Conflict of interest: None declared}

Ethical approval: The study was approved by the institutional ethics committee

\section{REFERENCES}

1. Zuckerman JD, Koval KJ. Fractures of the shaft of the humerus. In: Rockwood CA, Green DP, Bucholz RW,Heckman JD, editors. Rockwood and Green's Fractures in Adults. 4th ed. Philadelphia: Lippincott-Raven; 1996: 1025-1053.

2. Epps CH Jr, Grant RE. Fractures of the shaft of the humerus. In: Rockwood CA Jr, Green DP, Bucholz RW, editors. Rockwood and Green's fractures in adults. 3rd ed. Philadelphia: Lippincott Williams \& Williams; 1991: 843-869.

3. Praemer MA, Furner S, Price DP. Musculoskeletal conditions in the United States. Park Ridge (IL): Amer Acad of Orthopaedic Surgeons; 1992: 116.

4. Tsai CH, Fong YC, Chen YH, Hsu CJ, Chang CH, Hsu HC. The epidemiology of traumatic humeral shaft fractures in Taiwan. Int Orthop. 2009;33:4637.

5. Sarmiento A, Zagorski JB, Zych GA, Latta LL, Capps CA. Functional bracing for the treatment of fractures of the humeral diaphysis. J Bone Joint Surg Am. 2000;82(4):478-86.

6. Atroshi I, Gummesson I, Andersson B, Dahlgr E, Johannson A. The disabilities of the arm, shoulder and hand (DASH) outcome questionnaire. Acta Orthop Scand. 2000;71(6):613-8.

7. Gosler MW, Testroote M, Morrenhof JW, Janzing HMJ. Surgical versus non-surgical interventions for treating humeral shaft fractures in adults (Review). Cochrane Database Syst Rev. 2012;1:CD008832.

8. Foster RJ, Dixon GJ, Bach AW, Appleyard RW, Green TM. Internal fixation of fractures and nonunions of the humeral shaft. Indications and results in a multi-center study. J Bone Joint Surg Am. 1985;67(9):1448.

9. Bell MJ, Beauchamp CG, Kellam JK, Mcmurtry RY. The Result of plating Humerus shaft fractures in patients with multiple injuries .The sunny brook experience. J Bone Joint Surg Br. 1985;67:293-6.

10. Healy WL, White GM, Mick CA, Brooker AF, Weiland AJ. Nonunion of the humeral shaft. Clin Orthop. 1987;219:206-21.

11. Rutgers M, Ring D. Treatment of diaphyseal fractures of the humerus using a functional brace. $\mathrm{J}$ Orthop Trauma. 2006;20:597-601.

12. Mahabier KC, Vogels LM, Punt BJ, Roukema GR, Patka P, Van Lieshout EM. Humeral shaft fractures: Retrospective results of non-operative and operative treatment of 186 patients. Injury. 2013;44(4):42730 . 
13. Denard A Jr, Richards JE, Obremskey WT, TuckerMC, Floyd M, Herzog GA, et al. Outcome of nonoperative vs operative treatment of humeral shaft fractures: a retrospective study of 213 patients. Orthopedics. 2010;33(8):552.

14. Clement ND. Management of Humeral Shaft Fractures; Non-operative versus Operative. Arch Trauma Res. 2015;4(2):e28013.
Cite this article as: Kumar S, Shanmugam N, Kumar S, Ramanusan K. Comparison between operative and non operative treatment of fracture shaft of humerusan outcome analysis. Int J Res Orthop 2017;3:445-50. 